
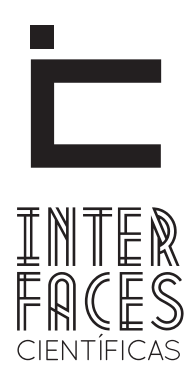

DIREITO

\title{
REGIME INTERNACIONAL DE COMBATE À CORRUPÇÃO E A PARTICIPAÇÃO POLÍTICO-NORMATIVA BRASILEIRA
}

INTERNATIONAL REGIME AGAINSTCORRUPTION ANOTHE BRAZILIANPOLITICAL-NORMATTUE PARTICIPATION

RÉGIMEN INTERNACIONAL PARA COMBATIR LA CORRUPCIÓN Y LA PARTICIPACIÓN POLÍTICA-NORMATIVA BRASILEÑA

\section{RESUMO}

O tema da corrupção, envolvendo funcionários de Estados, vem se tornando cada vez mais presente nas agendas internacionais, passando a representar objeto de interesses e preocupações dos atores e organizações do cenário global. Cresce, portanto, a consciência de que a disseminação de práticas como a cooptação ou o suborno de funcionários públicos para facilitar ou garantir negócios entre Estados e empresas é uma ameaça ao comércio internacional que não pode ser tolerada. Neste sentido, iniciativas políticas e norma- tivas têm procurado criar um regime internacional de combate à corrupção. 0 objetivo deste artigo é analisar a formação de um regime internacional de combate à corrupção e avaliar os esforços do Brasil para se adequar aos compromissos assumidos, a partir dos tratados internacionais que o país tem ratificado.

\section{PALAVRAS-CHAVE}

Regimes Internacionais. Corrupção. Brasil. 


\section{ABSTRACT}

Although the discussion about corruption involving state officials is still unobtrusive, the theme is becoming increasingly present in international agendas. It has become an interest and concern object among actors and organizations in the global scene. Therefore, people are becoming aware that co-opting and bribing public officials to facilitate or ensure business between States and companies is a threat to international trade and it cannot be tolerated. In this direction, policy and regulatory initiatives have been steadily undertaken in order to create an international regime able to fight corruption and provide actors tools to control and punish corrupt actions. The aim of this paper is to analyze the formation of an international regime to combat corruption and to assess Brazil's efforts to adjust commitments assumed from international treaties that the country has ratified.

\section{KEY WORDS}

International Regimes. Corruption. Brazil.

\section{RESUMEN}

El tema de la corrupción de funcionarios públicos es cada vez más presente en las agendas internacionales, $y$ ha sido objeto de los intereses y preocupaciones de los actores y organizaciones de todo el mundo. Ha ido creciendo la conciencia de que la difusión de prácticas como la cooptación o sobornar a funcionarios públicos para facilitar o garantizar los negocios entre estados y empresas es una amenaza para el comercio internacional que no puede ser tolerado. En este sentido, las iniciativas de política y reglamentación han tratado de crear un régimen internacional para combatir la corrupción. El objetivo de este trabajo es analizar la formación de un régimen internacional para combatir la corrupción y de evaluar los esfuerzos de Brasil para satisfacer los compromisos de los tratados internacionales que el país ha ratificado.

\section{PALABRAS CLAVE}

Régimen internacional; Corrupción; Brasil. 


\section{INTRODUÇ̄̃O}

No curso do processo civilizatório, principalmente quando agrupamentos sociais aprimoram aspectos culturais, éticos e morais, determinados conceitos vão sendo transformados a partir de novos valores. Ao discorrer sobre o comportamento humano, Eric Hobsbawn e Ranger (2002) cunhou o termo "tradições inventadas" para se referir a práticas introduzidas no meio social de maneira tácita ou explícita que, por sua reiteração, passam a assumir o valor de um costume ou tradição. Desta forma, comportamentos antes condenáveis socialmente podem passar a ser aceitos de maneira natural, bem como práticas e tradições ora tidas como normais podem converter-se em transgressões sociais.

Nesse sentido, as relações comerciais internacionais transigiram durante um considerável período histórico com hábitos que atualmente tendem a ser considerados condenáveis tanto do ponto de vista ético quanto legal. Assim, práticas como o oferecimento ou pagamento de valores realizados a autoridades estrangeiras para a concretização de acordos comerciais, o tráfico de influência política, a permissão e facilitação de ocultação patrimonial vêm sendo progressivamente tratadas com maior rigor pela comunidade internacional.

O objetivo precípuo deste artigo é o de analisar a formação de um regime internacional de combate à corrupção, mormente aquela relacionada a transações comerciais, envolvendo empresas e autoridades públicas estrangeiras e, pari passu, avaliar os esforços do Brasil para se adequar aos compromissos assumidos a partir dos tratados internacionais que têm ratificado com propósitos afins. Para tanto, foi realizada uma revisão bibliográfica em fontes diversificadas, priorizando-se, todavia, a exploração detalhada de tratados, planos, protocolos e outros instrumentos legais e políticos que possam ser considerados como partes de um conjunto global de iniciativas elaboradas em oposição a atividades corruptivas no comércio internacional.
Conveniente, aqui, apresentar o entendimento e a maneira pela qual se empregará o termo "regime internacional", porquanto ser um tema central neste estudo. Neste rumo, acompanhar-se-á o ensinamento de Krasner (1983), internacionalista norte-americano que, de sua produção literária, dedicou uma obra específica para tratar sobre este assunto, na qual regimes foram conceituados como conjuntos de normas e princípios sobre assuntos específicos e delimitados em que atores do cenário internacional apresentam expectativas convergentes.

\section{PODER, POLÍTICA, CORRUPÇÃO}

Uma abordagem conceitual do termo "corrupção" pode remeter um estudo que se pretenda fazer sobre o tema a uma infinidade de significados históricos, construções lógicas e aforismos distintos, o que não é o propósito deste artigo. Assim, adotando uma delimitação mais pragmática do termo, empregar-se-á aqui o vocábulo "corrupção" dentro de uma perspectiva mais ampla, como uma prática com capacidade lesiva de ofender o Estado de maneira expressiva, até mesmo porque assumindo este significado resta uma aproximação mais perceptível com a preocupação da comunidade internacional e seu respectivo empenho na construção de um regime internacional contra atos daquela natureza.

Etimologicamente, corrupção tem sua origem no latim, derivando de vocábulos com o sentido de romper, quebrar, adulterar. Remete, portanto, à ideia de desacordo ou desconformidade com aquilo que é o normal ou o correto. Em sua obra Confissões, Santo Agostinho (2001) elabora um raciocínio comparativo entre corrupção e mal, asseverando que aquilo que se corrompe não é completamente perfeito, pois se assim o fosse incorruptível seria, bem como não é completamente imperfeito, pois também assim não haveria o que se corromper. 0 que se corrompe, portanto, é naturalmente humano.

Justamente na possibilidade de investir contra essa deficiência derivada da condição humana dos 
agentes públicos é que se assenta a fraqueza explorada pelos corruptores do Estado. Não é por menos que uma proposta razoável de medida anticorrupção seja a mitigação de determinados poderes sobre processos decisórios ou de fiscalização, com a consequente implementação de camadas justapostas de jurisdição ou de atuação administrativa, o que, em tese, criaria maiores dificuldades em estabelecer um esquema criminoso de ofertas e recebimentos (ROSE-ACKERMAN, 1997).

No ambiente internacional, a corrupção que se materializa principalmente entre companhias estrangeiras e agentes públicos de outros Estados é a forma para a qual se dispende maior atenção. Os males decorrentes dessa prática escusa ultrapassam os limites de quaisquer ofensas criminais ora produzidas, provocando também graves consequências de natureza social, política, econômica e administrativa.

Há um entendimento predominante na produção científica sobre este assunto de que a corrupção é um problema global, que afeta a todos os países, de regimes democráticos ou não, mesmo que em escalas diferentes. Entretanto, os efeitos causados às nações mais pobres e em desenvolvimento tendem a ser sobremaneira mais perversos e agressivos, assim como aqueles países são os cenários nos quais geralmente aquela prática se dissemina mais facilmente (GLYNN ET AL., 2002).

De fato, durante um período recente da história mundial, a corrupção era não apenas considerada uma prática corriqueira, como inclusive era aceita formalmente, havendo Estados que permitiam até que empresas corruptoras deduzissem impostos de subornos ofertados em negócios realizados no exterior. Esta situação provocava sérios desajustes no mercado internacional, estimulando competições desiguais entre compradores e fornecedores de mercadorias, prestadores e tomadores de serviços, privilegiando aqueles que não tinham escrúpulos, mas possuíam capacidade de pagamento.

Além desta relação viciada entre companhias transnacionais e administrações públicas corruptas, a história também apresenta exemplos de episódios de corrupção, envolvendo diretamente governos distintos, principalmente em decorrência da polarização entre capitalismo e comunismo ocorrida durante a “Guerra Fria”. Neste sentido, Estados Unidos e União Soviética não se abstiveram em subsidiar lideranças governamentais com o propósito de garantir um alinhamento político e ideológico, mesmo tendo o conhecimento de que grande parte dos valores repassados para supostas destinações públicas seria desviada para o enriquecimento particular de líderes inescrupulosos.

Não são escassos os exemplos históricos nos quais próceres de países agraciados com financiamentos e subsídios de outros governos passaram a figurar como condenados, réus, acusados ou suspeitos de corrupção, podendo ser citados, como forma de ilustração, os casos do ex-presidente da Guatemala Alfonso Portillo, condenado pela Justiça dos Estados Unidos por recebimento de suborno do governo de Taiwan; do ex-presidente das Filipinas Ferdinand Emmanuel Edraín Marcos, condenado pelo tribunal anticorrupção daquele país por ter recebido reiterados subsídios dos Estados Unidos durante seu governo; de Hadji Mohamed Suharto, ex-presidente da Indonésia que ascendeu ao poder por meio de um golpe apoiado pelos Estados Unidos, posteriormente processado por práticas de corrupção; do ex-presidente da República do Congo (ex-Zaire) Mobutu Sese Seko, que também assumiu o poder após um golpe de Estado com o apoio norte-americano, acusado de acumular um vultoso patrimônio derivado da corrupção.

Com efeito, sobejam exemplos históricos similares aos ora mencionados, sobretudo em relação a ditadores de países da África e América Latina no decorrer da Guerra Fria. Em artigo, versando sobre o tema, Glynn e outros autores (2002) também estabeleceram a relação entre o financiamento de determinados governos e a corrupção, ao citar os exemplos como o de Ferdinand Marcos, nas Filipinas, da família Duvalier, no Haiti, e de Stroessner, no Paraguai. Segundo os autores, considerável parte do dinheiro enviado para aqueles países como auxílio internacional e socorro militar era, de fato, desviada para contas em paraísos 
fiscais dos grupos dominantes e seus apadrinhados, sendo que esta circunstância era de conhecimento notório dos financiadores dos recursos.

\section{HISTÓRICO DA FORMAÇÃO DO REGIME INTERNACIONAL CONTRA A CORRUPÇÃO - INICIATIVAS POLÍTICAS E MECANISMOS NORMATIVOS}

Antes do fortalecimento de uma percepção coletiva internacional da nocividade da corrupção para o desenvolvimento dos países não era raro que companhias que ultrapassavam suas fronteiras com o propósito de realizar transações com outros Estados utilizassem subterfúgios, moral e legalmente condenáveis para concretizar negócios. Efetivamente, dependendo da circunstância, havia até mesmo a possibilidade legal de declarar e deduzir impostos de pagamentos de subornos ofertados a funcionários públicos para garantir acordos comerciais.

A prática da corrupção internacional chegou a um patamar tão correntio que havia aqueles que não se detinham ao abordar o tema. Pelo contrário, chegavam a defender que, de acordo com o caso em específico, a adoção de atos corruptivos poderia representar um ganho para nações menos desenvolvidas, porquanto quebrariam entraves burocráticos que se consolidavam como barreiras ao pleno desenvolvimento e crescimento econômico, agilizariam o processo comercial/produtivo e diminuiriam custos operacionais derivados principalmente de cargas tributárias e fiscais sobejamente excessivas.

De forma paradoxal, o impulso decisivo para o início da construção de um regime internacional de combate à corrupção em práticas comerciais, envolvendo governos entre si e governos e empresas foi decorrente de um evento histórico que tinha a corrupção entrelaçada em sua gênese: o “caso Watergate". Após ter a imagem de sua condição moral comprometida pelo episódio que resultou na renúncia de seu presi- dente Richard Nixon em 1974, os Estados Unidos, sob a presidência de Jimmy Carter, decidiram adotar medidas políticas que pudessem de alguma forma restabelecer, ou ao menos melhorar, seu conceito perante a comunidade internacional.

Foi neste contexto que, em 1977, os Estados Unidos editaram o Foreign Corrupt Pratices Act (FCPA). Por este instrumento legal, aquele país passou a impor sanções administrativas e criminais a empresas e pessoas que, ao praticar atos comerciais com autoridades estrangeiras, utilizavam métodos corruptivos com o objetivo de consumar negócios. Desde então, ocorreram diversos casos processuais fundamentados em dispositivos daquela legislação envolvendo importantes companhias multinacionais, como a Monsanto, Siemens, Walmart, Avon, Lucent, entre outras (SAUDI-US..., 2012).

Ocorre que, com a adoção daquela nova postura política e normativa, as companhias norte-americanas começaram a ficar em uma difícil posição comercial, pois, no mercado internacional, enfrentavam concorrentes que não limitavam sua atuação por óbices legais de seus próprios países de origem, utilizando a oferta de subornos e pagamentos de propinas como um plus em suas transações comerciais, circunstância que não raro era decisiva na finalização de negócios em outros países. As empresas norte-americanas começaram então a pressionar seu governo, objetivando alterar aquela situação, o qual, por conseguinte, passou a pressionar a comunidade internacional para que fosse adotado um alinhamento de regras comerciais em escala global.

Muito vagarosamente e de forma bastante tímida, a pressão exercida pelos Estados Unidos começou a frutificar a partir de iniciativas regionais direcionadas a um tratamento diferenciado e específico da questão. Assim, quase vinte anos depois da promulgação da FCPA, em 29 de março de 1996, a Organização dos Estados Americanos adotou a Convenção Interamericana Contra a Corrupção, tratado multilateral que entrou em vigor a partir de 3 de junho de 1997, com a participação de quase a totalidade dos países americanos. 
A despeito de apresentar uma natureza normativa mais programática, aquela convenção dispôs relevantes abordagens sobre a questão, como o compromisso dos Estados signatários com sua adequação legislativa em temas como corrupção, suborno internacional e enriquecimento ilícito, a previsão de assistência e cooperação em investigações e processos penais atinentes e de medidas, buscando facilitar a identificação, localização, bloqueio, apreensão e confisco de bens. Outro interessante dispositivo presente na convenção encontra-se em seu artigo XIII, o qual determina que ela própria seja base jurídica suficiente de extradição para os crimes a ela relacionados, mesmo quando dois Estados parte não tenham assinado prévio tratado extraditório entre si (CONTROLADORIA..., 2007a).

0 ano de 1997 teve um destaque especial na formação e consolidação de um regime internacional de combate à corrupção, principalmente a partir da adoção da Convenção Sobre o Combate da Corrupção de Funcionários Públicos Estrangeiros em Transações Comerciais Internacionais, adotada pela Organização para a Cooperação Econômica e o Desenvolvimento (OCDE), que passou a viger em fevereiro de 1999 (CONTROLADORIA..., 2007a).

Também de natureza programática, este foi o primeiro mecanismo internacional não regional a delinear compromissos de criminalizar a corrupção de agentes públicos estrangeiros em transações comerciais, estabelecendo medidas de monitoramento de países e mecanismos de vigilância para assegurar sua efetiva implementação. Além de sua aplicação abranger os trinta e quatro países membros daquela organização internacional, outros quatro países aderiram ao tratado, dentre eles o Brasil. Assim, como na Convenção Interamericana, este tratado tem força como fundamento de extradição entre os signatários em casos dos crimes nele previstos.

Ainda em 1997, a União Europeia adotou o Tratado da União Europeia na Luta Contra a Corrupção Envolvendo Oficiais da Comunidade Europeia ou Oficiais de Estados Membros da União Europeia, documento no qual são traçadas intenções para a adoção de iniciativas e medidas administrativas e legais contra práticas, envolvendo temas afins à corrupção (EUROPEAN..., 1998).

Em reforço ao regime internacional sobre o tema, dois outros importantes tratados regionais foram adotados em 1999 pela União Europeia: a Convenção Sobre Legislação Civil Contra a Corrupção (COUNCIL..., 1999) e a Convenção Sobre Legislação Penal Contra a Corrupção (COUNCIL..., 2015).

Dentre as proposições civis, algumas se destacam como a assunção de compromissos para garantir ferramentas de compensação de danos para as vítimas de atos de corrupção; responsabilização do Estado por atos praticados por seus servidores; proteção de empregados que colaborem com informações de práticas suspeitas; cooperação em casos de investigações internacionais, entre outros. Dos compromissos criminais assumidos, podem ser destacados os relativos à criação de tipificação penal relativa à corrupção de servidores públicos, organizações internacionais, parlamentos e assembleias; o tráfico de influência; as imunidades; a proteção a colaboradores da justiça e testemunhas; a extradição; a aplicação territorial da lei, entre outros pontos.

Em novembro de 2000, foi adotada pela Organização das Nações Unidas (ONU) a Convenção das Nações Unidas Contra o Crime Organizado Transnacional, comumente denominada Convenção de Palermo. Apesar de tratar do fenômeno criminológico internacional de uma forma mais ampla, esta convenção não deixou de abordar o tema da corrupção, tendo-lhe destinado tópicos específicos para sua criminalização e medidas de combate (PRESIDÊNCIA..., 2015).

Tão logo foi adotada a supradita convenção, a Assembleia Geral das Nações Unidas se reuniu em dezembro de 2000 e reconheceu a necessidade de um instrumento legal internacional específico contra a corrupção. Foi assim que, em outubro de 2003, adotou-se a Convenção das Nações Unidas Contra a Corrupção, um tratado que trouxe para o âmbito da ONU o tratamento deste problema de uma forma bem mais completa, abordando temas como políticas de prevenção à corrupção, códigos de conduta para funcionários públicos, a participação da sociedade civil, 
a cooperação entre organismos nacionais e internacionais, mecanismos para a recuperação de ativos, solução de controvérsias entre tantos outros temas (ORGANIZAÇÃO..., 2015).

Indispensável destacar que além dos documentos ora mencionados, há uma série de outros tratados, planos, resoluções e protocolos regionais que também fazem parte de um regime internacional de combate à corrupção. Entretanto, para os propósitos deste artigo, não se afigura substancial uma abordagem mais pormenorizada de todos os institutos de formação deste regime, mas sim a construção de uma percepção de sua existência e importância. Até mesmo porque, se fosse o caso de estender este estudo nessa direção, não poderiam ser olvidados determinados organismos internacionais que tem uma atuação profunda e direta na questão da corrupção global, como é o caso do Escritório das Nações Unidas Sobre Drogas e Crime (UNODOC), da Transparência Internacional, da Câmara Internacional do Comércio, do Grupo de Estados Contra a Corrupção do Conselho da Europa (GRECO) e outros.

\section{EMPENHO POLÍTICO, LEGISLATIVO E ADMINISTRATIVO BRASILEIRO EM CONSONÂNCIA COM O REGIME INTERNACIONAL CONTRA A CORRUPÇÃO}

O Brasil é um dos membros que adotou a Convenção Interamericana Contra a Corrupção desde a sua origem, em 29 de março de 1996, tendo concluído o processo de ratificação do tratado em 10 de julho de 2002, com o conseguinte depósito de instrumento em 24 de julho de 2002. Da mesma sorte, participando como Estado convidado, o Brasil adotou a Convenção Sobre o Combate da Corrupção de Funcionários Públicos Estrangeiros em Transações Comerciais Internacionais da OCDE, em 17 de dezembro de 1997, tendo-lhe ratificado em 15 de junho de 2000. Em referência à Convenção das Nações Unidas Contra a Corrupção, o
Brasil assinou sua adoção em 9 de dezembro de 2003, com a posterior ratificação em 15 de junho de 2005.

No plano interno, o Brasil vem implementando legislações na tentativa de se adequar aos compromissos firmados por meio dos tratados dos quais é signatário. Neste sentido, a primeira importante atualização legislativa foi a Lei 10.467 de 11 de junho de 2002, pela qual foi criado um novo capítulo no Código Penal Brasileiro, sob o título “Dos Crimes Praticados por Particular Contra a Administração Pública Estrangeira”, tendo sido acrescentados dois novos tipos penais: a Corrupção Ativa em Transação Comercial Internacional (Código Penal Brasileiro, Art. 337-B) e o Tráfico de Influência em Transação Comercial Internacional (Código Penal Brasileiro, Art. 337-C). É preciso destacar que, tanto para um quanto para o outro crime, é necessário que o ato corruptivo ou o tráfico de influência atendam a duas condições: que sejam relacionados a um funcionário público estrangeiro e a uma transação comercial internacional (BRASIL, 2002).

Esta circunstância atende ao ajuste firmado na Convenção Sobre o Combate da Corrupção de Funcionários Públicos Estrangeiros em Transações Comerciais Internacionais da OCDE, que teve como uma de suas maiores preocupações a criação de mecanismos para que os países pudessem alcançar seus corruptores em práticas, quando, realizando atos no comércio internacional, ou seja, trata-se de um remédio legal de natureza criminal para atacar a demanda feita pelo corruptor, não a oferta feita pelo corrompido, contra o qual deve haver outros institutos penais apropriados.

Buscando regulamentar uma prática que era relativamente comum no serviço público, em 23 de novembro de 2000, a Presidência da República adotou a Resolução $n^{\circ} 03$, disciplinando o recebimento de presentes de qualquer valor por autoridades públicas, norma também adequada a uma situação de oferecimentos indevidos em atividades comerciais, envolvendo empresas estrangeiras e servidores públicos (BRASIL, 2000).

Da mesma forma, em conformidade com os dispositivos da convenção da OCDE, principalmente dentro 
do contexto histórico no qual países aceitavam a declaração de pagamentos de subornos a autoridades estrangeiras na realização de negócios comerciais no exterior, a Receita Federal do Brasil publicou em 2009 o Ato Declaratório Interpretativo $n^{\circ} 32$, pelo qual esclareceu a impossibilidade de dedução tributária dos pagamentos

[...] efetuados a título de recompensa pela prática de infrações legais ou a elas relacionadas, em especial aquelas mencionadas no artigo 1 da Convenção sobre o Combate da Corrupção de Funcionários Públicos Estrangeiros em Transações Comerciais Internacionais. (RECEITA..., 2009, [s.p.]).

\section{LEI ANTICORRUPÇÃO - A INICIATIVA BRASILEIRA MAIS RECENTE DE COMBATE À CORRUPÇÃO EM TRANSAÇÕES COMERCIAIS INTERNACIONAIS}

No dia $1^{\circ}$ de agosto de 2013 foi sancionada a Lei $n^{\circ} 12.846$, que passou a ser identificada comumente como Lei Anticorrupção, tendo sua vigência iniciada a partir do dia 29 de janeiro de 2014. Oriundo de um Projeto de Lei trabalhado em conjunto pela Controladoria Geral da União, Advocacia Geral da União e Ministério da Justiça, este novo dispositivo legal veio somar-se às iniciativas brasileiras dentro do contexto esculpido pelos acordos internacionais subscritos.

Diferente das legislações anteriormente produzidas, este novo instituto legal direciona seu foco para as pessoas jurídicas que por ventura busquem utilizar métodos de corrupção e fraudes em licitações e contratos administrativos para garantir ou consumar transações comerciais com a Administração Pública nacional ou estrangeira. É uma lei de natureza civil e administrativa que estabelece a responsabilização objetiva de pessoas jurídicas, sem, contudo, afastar a responsabilidade administrativa, civil e criminal dos atos praticados individualmente por seus dirigentes ou administradores (BRASIL, 2013).

Juntamente com a Mensagem Presidencial que en- caminhou ao Congresso Nacional o respectivo Projeto de Lei, foi acostada a EMI n0011/2009, documento que apresentou as justificativas para a elaboração daquele novo regramento legal. De seu conteúdo, relevante observar a preocupação governamental com a adequação da legislação pátria aos acordos ratificados pelo Brasil nesta área temática, apresentando, particularmente, o esclarecimento sobre a lacuna legal então existente em relação aos atos praticados ilicitamente pelas pessoas jurídicas no exercício de atos comerciais:

\begin{abstract}
Com as três convenções, o Brasil obrigou-se a punir de forma efetiva as pessoas jurídicas que praticam atos de corrupção, em especial o denominado suborno transnacional, caracterizado pela corrupção ativa de funcionários públicos estrangeiros e de organizações internacionais. Dessa forma, urge introduzir no ordenamento nacional regulamentação da matéria - do que, aliás, o país já vem sendo cobrado -, eis que a alteração promovida no Código Penal pela Lei n 10.467 , de 11 de junho de 2002, que tipificou a corrupção ativa em transação comercial internacional, alcança apenas as pessoas naturais, não tendo o condão de atingir as pessoas jurídicas eventualmente beneficiadas pelo ato criminoso (CONTROLADORIA..., 2009, [s.p.]).
\end{abstract}

A opção por firmar a responsabilidade civil e administrativa no novo mecanismo legal, também, foi objeto de exposição naquela mesma mensagem, restando clara a preocupação em estabelecer formas mais práticas e efetivas de alcançar as empresas que buscassem meios indevidos no trato com a Administração Pública nacional ou estrangeira:

\footnotetext{
Observe-se que o presente projeto optou pela responsabilização administrativa e civil da pessoa jurídica, porque o Direito Penal não oferece mecanismos efetivos ou céleres para punir as sociedades empresárias, muitas vezes as reais interessadas ou beneficiadas pelos atos de corrupção. A responsabilização civil, porque é a que melhor se coaduna com os objetivos sancionatórios aplicáveis às pessoas jurídicas, como por exemplo o ressarcimento dos prejuízos econômicos causados ao erário; e o processo administrativo, porque tem-se revelado mais célere e efetivo na repressão de desvios em contratos administrativos e procedimentos licitatórios, demonstrando melhor capacidade
} 
de proporcionar respostas rápidas à sociedade. (CONTROLADORIA..., 2009, [s.p.]).

Os atos, condenáveis pela nova lei, harmonizam-se com os prescritos nos acordos internacionais já assinados. Desta forma, foram abarcadas, no artigo $5^{\circ}$, a promessa ou oferta de vantagens indevidas a agente público, o financiamento, custeio ou patrocínio dos mesmos atos, a utilização de terceiros, pessoas físicas ou jurídicas, para a dissimulação em negócios, a fraude ou perturbação de procedimentos licitatórios, entre outros (BRASIL, 2013).

As sanções administrativas limitam-se a multas que não deverão ser aplicadas em valor inferior ao ganho obtido ilicitamente. A instauração e julgamento do processo administrativo são de competência da autoridade máxima de cada Poder, sendo que, no caso do Poder Executivo Federal, a Controladoria Geral da União (CGU) terá competência concorrente. Os atos praticados contra a administração pública estrangeira no exterior também serão processados e julgados pela CGU (BRASIL, 2013).

A responsabilização administrativa não afastará a possibilidade de responsabilização civil na esfera judicial, sendo que todos os entes federativos são legitimados para a propositura das ações por meio de suas respectivas advocacias públicas. Ao contrário das consequências administrativas, na seara civil há várias possibilidades de sanções, como o perdimento de bens, direitos e valores, a suspensão ou interdição de atividades, a dissolução compulsória da pessoa jurídica e a proibição de recebimento de incentivos, subsídios e financiamentos estatais (BRASIL, 2013).

Outro importante dispositivo em consonância com os pactos assumidos internacionalmente está consignado no artigo 28, o qual prenuncia a possibilidade de aplicação da lei às pessoas jurídicas brasileiras que venham a praticar os atos ilícitos nela contidos contra a administração pública estrangeira, mesmo quando praticados no exterior.

A despeito da novidade e das possibilidades de atuação criadas pela lei em comento, ainda é bastante incipiente sua utilização, mormente, considerando o curto prazo de sua vigência, bem como a falta de um decreto que a regulamente. Nada obstante, as ferramentas necessárias para desestimular atos espúrios de empresas no trato com a administração pública, nacional ou externa, estão agora postas à disposição, o que corresponde com os anseios da comunidade internacional, reiteradamente expressados em tratados e outros protocolos de intenções.

\section{CONSIDERAÇÕES FINAIS}

As consequências da corrupção em transações comerciais internacionais não devem ser resumidas a questões éticas ou legais. De fato, os resultados da disseminação dessa prática em uma escala global podem representar sacrifícios e prejuízos muito mais severos em variados temas, como na economia, no desenvolvimento humano, na política, no crescimento dos países, na aplicação da justiça, na distribuição de bens, entre tantos outros temas que poderiam aqui ser citados.

Numericamente, os efeitos econômicos da corrupção sobre um país já foram demonstrados. Em conformidade com um estudo conduzido pelo economista do Fundo Monetário Internacional Paolo Mauro (2002), os custos da corrupção são, consideravelmente significativos, com reflexos diretos no nível de investimentos públicos e no crescimento econômico. Outros prejuízos podem ser considerados a partir da redução dos fluxos de auxílio governamentais em decorrência dos desvios de verbas de projetos originais; a perda de arrecadação tributária; a substituição do trabalho produtivo pelo parasitismo; a afetação da composição das despesas do governo, a partir da preferência de determinados tipos de gastos em que haja mais facilidade para a coleta de subornos e a manutenção do sigilo.

0 antigo argumento de que a corrupção poderia contribuir para o crescimento de nações ao eliminar etapas burocráticas e, dessa forma, acelerar investimentos e possibilitar a execução de projetos não pode deixar de ser considerado um sofisma para 
justificar uma prática socialmente corrosiva. Inconteste afirmar que em algum momento os custos da corrupção serão deduzidos, seja pelo superfaturamento do projeto inicial, pelo posterior aumento orçamentário de conclusão de um empreendimento, pela utilização ou entrega de materiais de qualidade inferior, pela sonegação tributária decorrente da falta de fiscalização pelo enfraquecimento da competitividade no mercado.

Glynn e outros autores (2002) manifestaram preocupações de natureza congênere, ao afirmar que, de forma generalizada, a corrupção é uma ameaça à economia mundial multilateral, posto que ela dependa diretamente da confiança existente entre os participantes de que os outros vão proceder em conformidade com o que lhes cabe. A corrupção, assim, seria um elemento de instabilidade permanente para o sistema econômico internacional, distorcendo a competição, reduzindo os ganhos do livre comércio e do livre investimento e afastando os atores que não toleram participar de esquemas ignóbeis ou não tenham condição de assim proceder.

No desenvolvimento de sua teoria sobre os motivos que contribuem para a cooperação no cenário internacional, Arthur Stein (1990) afirma que os países tendem a colaborar entre si a partir de dilemas decorrentes de interesses ou aversões comuns, que os levam tanto a buscar ou a manter alguns resultados, assim como a afastar outros. 0 aperfeiçoamento de uma consciência global mais elaborada a respeito das vantagens de propiciar um mercado internacional menos maculado por práticas desonestas vem possibilitando uma transformação de antigos hábitos, fazendo com que a corrupção passe a se tornar uma aversão comum a grande parte dos Estados.

É inegável que não há uma solução que resolva de forma definitiva esse problema. Sem embargo, a existência de uma preocupação mundial e o fato de que ela vem se ampliando é motivo suficiente para cultivar perspectivas favoráveis sobre o futuro das relações internacionais.

\section{REFERÊNCIAS}

AGOSTINHO, S. Confissões. Lisboa: Lusofonia, 2001.

BRASIL. Código penal brasileiro. Disponível em: <http://www.planalto.gov.br/ccivil_03/decreto-lei/ del2848.htm> Acesso em: 15 jul. 2015.

BRASIL. Resolução $n^{0}$ 3, de 23 de novembro de 2000. Disponível em: <http://www.planalto.gov.br/ ccivil_03/codigos/codi_Conduta/resolucao3.htm> Acesso em: 15 jul. 2015.

BRASIL. Lei n⿳0 10.467, de 11 de junho de 2002. Disponível em: <http://www.planalto.gov.br/ccivil_03/ leis/2002/L10467.htm>. Acesso em 15 nov. 2015.

BRASIL. Lei $\mathbf{n}^{\mathbf{0}} \mathbf{1 2 . 8 4 6}$, de $1^{\circ}$ de agosto de 2013. Disponível em: <http://www.planalto.gov.br/ ccivil_03/_ato2011-2014/2013/lei/l12846.htm>. Acesso em: 23 nov. 2015.

CONTROLADORIA Geral da União. Convenção interamericana contra a corrupção. Brasília: CGU, $2007 a$.

\section{CONTROLADORIA Geral da União. Convenção da OCDE sobre o combate da corrupção de funcionários públicos estrangeiros em transações comerciais internacionais. Brasília: CGU, 2007b.}

CONTROLADORIA Geral da União/Ministério da Justiça/Advocacia Geral da União. EMI n00011 2009, de 23 de outubro de 2009. Disponível em: <http://www.camara.gov.br/proposicoesWeb/ prop_mostrarintegra?codteor $=735505 \&$ filen ame $=$ Tramitacao-MSC+52/2010+\%3D\%3E+ PL+6826/2010>. Acesso em: 25 nov. 2015.

\section{COUNCIL of Europe. Civil law convention on} corruption: and explanatory report. Strasbourg: Council of Europe Publishing, 1999. 
COUNCIL of Europe. Criminal law convention on corruption. Disponível em: <http://www. uhdigm.adalet.gov.tr/sozlesmeler/coktaraflisoz/ ak\%5Cingilizce\%5C173_ing.pdf>. Acesso em: 15 out. 2015.

EUROPEAN Union. Convention on the Fight against Corruption Involving Officials of the European Communities or Officials of Member States of the European Union. International Legal Materials, v.37, n.1, Washington, jan. 1998. p.12-21.

GLYNN, Patrick et al. A Globalização da Corrupção. In: ELLIOT, Kimberly Ann (Org.). A corrupção e a economia global. Brasília: Universidade de Brasília, 2002.

HOBSBAWN, Eric; RANGER, Terence (Org.). A invenção das tradições. São Paulo: Paz e Terra, 2002.

KRASNER, Stephen D. Structural causes and regime consequences: regimes as intervening variables. In: KRASNER, Stephen D., International Regimes. Ithaca: Cornell University Press, 1983.

ORGANIZAÇÃO das Nações Unidas. Convenção das Nações Unidas contra a corrupção. Disponível em: <https://www.unodc.org/documents/lpo-brazil// Topics_corruption/Publicacoes/2007_UNCAC_Port. pdf>. Acesso em: 20 nov. 2015.
PRESIDÊNCIA da República. Convenção das Nações Unidas contra o Crime Organizado Transnacional. Disponível em:

<http://www.planalto.gov.br/ccivil_03/_ato20042006/2004/decreto/d5015.htm>. Acesso em: 25 jun. 2015.

\section{RECEITA Federal. Ato declaratório interpretativo}

RFB n 32, de 15 de outubro de 2009. Disponível em: <http://www.receita.fazenda.gov.br/Legislacao/ AtosInterpretativos/2009/\%20ADIRFB032.htm>. Acesso em: 20 out. 2015.

ROSE-ACKERMAN, Susan. A Economia Política da Corrupção. In: ELLIOT, Kimberly Ann (Org.).

A Corrupção e a Economia Global. Brasília: Universidade de Brasília, 2002.

\section{SAUDI-US Trade Group. Are Members of Royalty "Foreign Officials" Under the FCPA?, 2012. Disponível em: <http://sustg. org/tag/fcpa/>. Acesso em: 15 jul. 2014.}

STEIN, Arthur A. Why Nations Cooperate. Ithaca: Cornell University Press, 1990.
1. Bacharel em Direito, mestrado em andamento em Ciência Política (UFG) e Agente de Polícia Federal na função de Adido Policial Adjunto na Embaixada do Brasil em Roma. E-mail: fredegulho@gmail.com

2. Doutora em Relações Internacionais (UNB). Professora da Graduação em Ciências Econômicas e do Programa de Pós-Graduação em Ciência Política (PPGCP) da Universidade Federal de Goiás (UFG). E-mail: andflucena@gmail.com 
